\title{
Optimized Hybrid Wind-Diesel Energy System with Feasibility Analysis
}

\author{
Sk. Shezan Arefin ${ }^{1} \cdot$ Narottam Das $^{1}$
}

Received: 30 November 2016 / Accepted: 10 June 2017 / Published online: 28 June 2017

(C) Springer Nature Singapore Pte Ltd. 2017

\begin{abstract}
The enormous percentage of people in the world; particularly in the developing countries; are living mostly in decentralized, rural and remote areas, those are geographically secluded from the main grid connection. The power distribution and continuous fuel transportation to generate electricity for these areas pretenses a very big challenge. By proper utilization of renewable energy resources in off grid hybrid energy systems will be an efficient solution of this crisis. Moreover, the high cost of renewable energy systems has led to its slow adoption in many developing countries. Hence, it is very important to find an appropriate size of system in order to reduce the energy cost and excess electricity generation as well as to maximize the available resources. Therefore, a hybrid energy system has been designed and simulated to support a small community considering an average load demand of $85 \mathrm{kWh} / \mathrm{d}$ with a peak load of $8.7 \mathrm{~kW}$. The simulation and optimization of the system have been performed by the HOMER software using real time field data of solar radiation, wind speed and biomass of that particular area. The simulation results confirm that the system is suitably feasible with respect to the net present cost (NPC) and $\mathrm{CO}_{2}$ emission reduction purpose. The simulation results also confirm that the NPC and $\mathrm{CO}_{2}$ emission can be reduced about $32.45 \%$ and 29 tons per year respectively compared to the conventional power plants. The NPC of the optimized system has been found about USD \$160,626 having per unit Cost of Energy
\end{abstract}

Narottam Das

Narottam.Das@usq.edu.au

1 School of Mechanical and Electrical Engineering, Faculty of Health, Engineering and Sciences, University of Southern Queensland, Toowoomba, QLD 4350, Australia
(COE) about USD $\$ 0.431 / \mathrm{kWh}$ and the operating cost USD $\$ 10,779 / \mathrm{yr}$.

Keywords Index terms - HOMER - Load demand . Optimization · Renewable energy $\cdot$ Sustainable development and wind turbine

\section{Introduction}

In present situation, the most challenging fact in the world is energy security and climate change. This complicated task of conducting research is extended radically where the attainment issues are social, economic, technological, environmental, risk management, and geopolitical $[1,2]$. The most important part is the demand of energy which is rapidly growing. Moreover, the climate change and global warming are two main concerns because of the increase of greenhouse effects. The use of fossil fuel is increasing day by day at an alarming rate. Due to the excessive utilization of fossil fuel creating a detrimental effect on the environment.

Nowadays, voltage fluctuation due to the variation of wind speed is an important issue. Besides, a radical shift to a decarbonize energy supply will be required to stable the atmospheric concentrations of $\mathrm{CO}_{2}$ which leads a significant climate change mitigation. So, it is very urgent to arrange the renewable energy resources for this critical issue [3, 4]. Usage of renewable energy resources for electricity generation is a priority research topic for this situation. Remarkable efforts to expand the sources of various forms of energy to intensify a deployment of renewable and sustainable energy slots have been increasing all over the humanity. The first priority in intensifying renewable energy deployment in 21 st century is the combined effects 
of the depletion of fossil fuels and the awareness of environmental degradation $[5,6]$. Therefore, the policy makers and researchers are paying more attention to conduct research in this area. For an instance, before 2020 the European Union countries aim to use the renewable sources and get at least $30 \%$ of its potential energy [7, 8]. There are various renewable energy resources such as biomass, wind, geothermal energy, solar, hydro-electric and tidal power. The hybrid renewable energy resources can reduce the emission of harmful gases and reduce the use of imported power $[9,10]$. Australia is blessed with abundant resources especially the potential renewable energy, such as huge amount of wind sources, biomass and the larger global solar radiation contains due to its geographical position [11, 12]. During the last two decades, electrical energy consumption in Bangladesh has increased significantly due to dramatic economic expansion and the lack of measurement of energy preservation. It is expected that peak loads will reach to 65 GW in 2027 which causes over $\$ 100$ billion might be the total investment. Therefore, for sustainable development, an imperative need to build up policies of energy conservation $[13,14]$. The fossil fuels has been used to generate most of the electrical power [15], neglecting the use of its renewable energy resources such as wind, biomass and solar to generate electricity.

Aside from nearby preservation endeavors, with expanding burden interest and an unnatural weather change, arrangement producers are taking a gander at environmentaccommodating sort of vitality and force assets to maintain the world's remained vitality for the future era individuals $[9,16]$. For the force gadgets innovation, the utilization of integrator with the vitality assets and vitality payload space framework is the new development. To full fill the heap requests, the wind and sun powered assets can be assumed a noteworthy part $[17,18]$.

At present, the installation process of a hybrid energy system is getting easier and flexible. The hybrid energy system is economically, environmentally feasible, and reliable. As a result, the great attractions with the similar power production systems have been all over the world. However, the number of renewable energy resources has been increased dramatically $[19,20]$. Meanwhile, there are some important factors such as regulations, costs, and incentives etc. which should be given priority for the rapid change of energy environment. For example, focus on Indonesian energy scenario of fossil fuel where it shows that there is an unfavorable effect on their economy. Mostly, they depend on these fossil fuels which are burned, causes the environmental effects i.e. greenhouse gas emission. Furthermore, rapid annual growth rate is about $7 \%$ of Indonesian energy consumption have been recorded after the economic recession in 1998. Although there is limited reservation of fossil fuels but still a high dependency on it. It is a clear indication of increased energy consumption as an economic recovery. After the household sectors, industrial and transportation sectors become the highest energy consumers [21, 22]. Therefore, time has come to take serious action to give priority by the government for adopting renewable energy [23]. Thus, solar energy, hydropower, geothermal energy are such renewable energy sources which can solve this problematic issue. This renewable energy supply can help to lower the emission and decrease the higher emission rate [24]. Utilization of renewable energy is effective only because of higher fuel price in world market [25]. So far, the expansion of electricity generation is badly affected due to hike the prices of fossil fuels and this increment varied about $1.5 \%$ in a year [26]. There are five main islands, such as Kalimantan, Sumatra, Sulawesi, Papua and Java which are surrounded by smaller Islands. Those islands are facing the problem of energy demand due to the dependence on the fossil fuels. Thus, it costs so high for transportation of fossil fuel supply from islands to islands [27]. If the natural sources of energy are broadly used then it may stable and balance the fuel price in the market. It may also minimize the dependency of non-renewable energy in near future. The electricity fuel mix for the 10 ASEAN countries in 2007 is illustrated in Fig. 1. The utilization of solar and wind energy system has become increasingly popular due to modular and environment friendly nature. The field of solar-wind has experienced a remarkable growth for the last two decades in its wide spread use of stand-alone to utility interactive solar-wind systems. The stand-alone hybrid energy system is getting the popularity day by day. Power is an imperative variable for industrialization, urbanization, money related development of any nation. There are diverse sorts of conventional and non-traditional vitality sources used to generate power. Sunlight based and wind vitality framework is a standout amongst the most conspicuous wellsprings of vitality. The usage of sun oriented and wind vitality framework has turned out to be progressively prevalent because of particular and environment well-disposed nature.

The scientists consider wind speed and load conjectures mistake and slope rate of ordinary warm units to decide framework hold edges in the wind-hydro-warm interconnected Swedish power framework. Thought is given to the connection of wind homestead gauges inside a locale and between diverse locales and connections there serve levels to a likelihood of as well low a recurrence because of the load and wind vacillations. The Swedish framework has a requirement to serve pool for recurrence control partitioned to that of the save apportioned or assigned for generator and transmission line trips. To be that it may not the situation in numerous power frameworks. Various researchers analyzed the effect of wind power limit on generator stacking levels, the framework hold accessibility furthermore, generator 


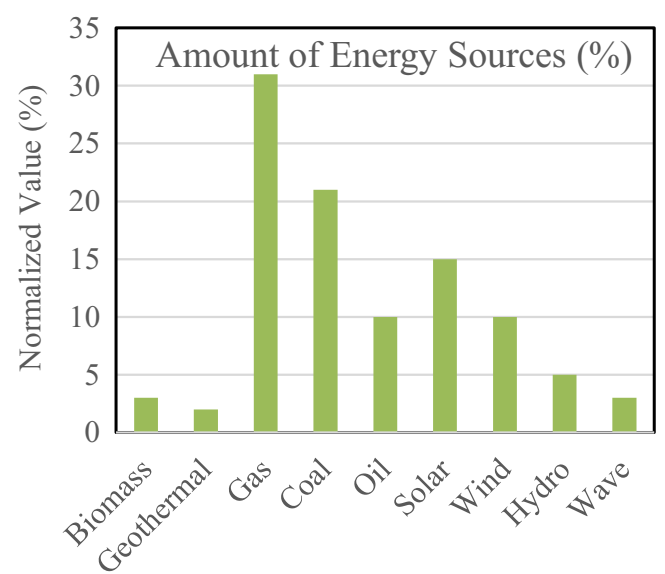

Fig. 1 Amount of energy sources contribution from all over the world [28]

inclining rates. The creators recommend the accessibility of framework will rely on upon whether the anticipated wind power is fused into the unit responsibility [28]. One of the researcher endeavors to measure the specialized results of high wind entrances regarding essential, auxiliary and long haul save as they apply to the interconnected German power framework furthermore, recommends it will bring about a considerable change in the interest for certain sorts of hold with the hybrid renewable energy system

Now, the electrification rate in Indonesia is about $71 \%$ [29]. From the survey, it can be said that most of the remaining $29 \%$, about $80 \%$ reside in rural areas and almost all outside of the most populated islands, Java and Bali. Most of the poor people in Indonesia live in the countryside, small islands where it's difficult to access or even limited access to electricity supply. Meanwhile, electricity demand also growing so fast in rural areas. In this study, renewable, nonrenewable energy, and the importance of renewable energy is discussed. Besides, it has been illustrated the proceeding of reducing $\mathrm{CO}_{2}$. Indonesia power producing through renewable system also report in this paper. Furthermore Section 7, proposed a technique that combined different renewable systems for overcoming the limitations of using individual renewable energy in Indonesia.

\section{Methodology}

In general, month to month besides annual wind velocity information have already gathered intended for monthly climatological data collected from Indonesian climatological office. Besides, the branch of Day Labor and Regulation (DLR), Germany has showed a strategy for usual wind speed yield is tried for particular separation of region besides commencing the Malaysian climatological division considered information has gathered for Indonesia.
In Fig. 2, a complete schematic diagram of a WindDiesel Hybrid renewable energy system has been illustrated. According to the meteorological data and the load demand, a complete design of hybrid energy has been introduced. An AC diesel generator has been connected with the AC Busbar. On the DC Bus-bar, the wind turbine and battery bank have been connected. The energy conversion process will be conducted through the number of converters. The battery storages and converters have been synchronized according to the load demand and the electrical appliances. The charge controller and voltage regulator also connected with the converter and power supply. Usually, the power distribution process is conducting according to the priority basis of power supply.

In NEM season, high wind speed and heavy rainfall affects the tourism business significantly. Consequently, the load profile of this resort is high during Southwest Monsoon (SWM; May to September), First Inter monsoon (FIM; March to April), and Second Inter monsoon (SIM; October to November) seasons and slightly low in Northeast Monsoon (NEM; December to February) season [30]. Estimated hourly load data of one year served as the input into HOMER software taking day to day load variance of $10 \%$ and time step of $15 \%$. Estimated peak load and average load per day were $1,185 \mathrm{~kW}$ and $13,048 \mathrm{~kW}$, respectively. The list of electrical appliances employed and their power rating is shown in Table 1, while the estimated load profile for one year is shown in Fig. 3. The flow chart in Fig. 4 describes the control and power management strategy of the off-grid HRES with diversion load. According to this block diagram and power management strategy, the master controller

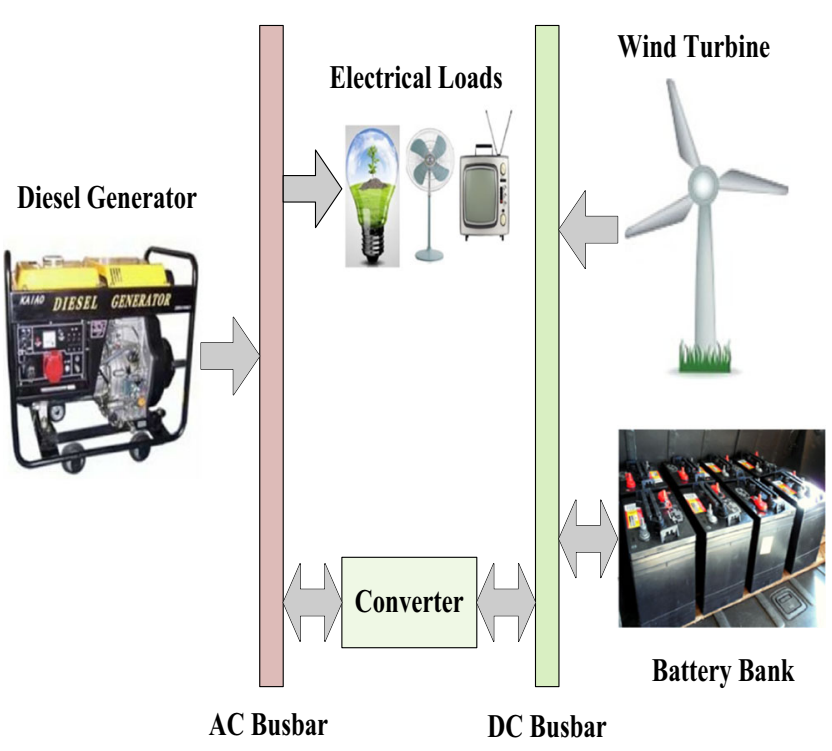

Fig. 2 Schematic diagram of a wind-diesel hybrid energy conversion system 
Table 1 Assumed load and its power rating

\begin{tabular}{llll}
\hline Name of appliances & Qty. & Running hour/day & Power rating (Watt) \\
\hline Air conditioning & 50 & 12 & 1,400 \\
Cable TV & 45 & 5 & 160 \\
Tube light & 300 & 12 & 30 \\
Table light & 250 & 5 & 20 \\
CFL bulb & 50 & 8 & 42 \\
Overhead projector & 2 & 4 & 350 \\
Slide projector & 2 & 4 & 250 \\
Microphone & 10 & 2 & 15 \\
Refrigerator & 50 & 12 & 350 \\
Hair dryer & 50 & 3 & 2,400 \\
Coffee maker & 50 & 3 & 1,400 \\
Ceiling fan & 100 & 8 & 80 \\
Oven & 10 & 5 & 3,400 \\
Desktop computer & 10 & 12 & 120 \\
Laptop computer & 20 & 12 & 80 \\
Freezer & 35 & 12 & 400 \\
Printer & 2 & 3 & 100 \\
Scanner & 2 & 3 & 10 \\
\hline
\end{tabular}

will always monitor the output power of PV, wind, diesel generators andstate of charge (SOC) of batteries. Besides, this master controller will make sure that the batteries are not charging with electricity from diesel generator. When the output power from renewable sources $\left(\mathrm{P}_{\text {ren.out }}\right)$ greater than load demand $\left(\mathrm{P}_{\text {load }}\right)$ then master controller will allow the battery to stores the renewable energy. The master controller will give a command to the auxiliary controller to operate relay connected to diversion load, when the SOC of battery is maximum. So, the diversion load will work only when the batteries are over charged or the system has excess electricity. On the other hand, when the output power from renewable sources $\left(\mathrm{P}_{\text {ren.out }}\right)$ is less than the load demand $\left(\mathrm{P}_{\text {load }}\right)$ then master controller will use storage batteries as back up until storage batteries reached at minimum SOC [31-34].

\section{Techno-Economic Analysis}

Techno-economic analysis is very essential to suggest an optimal combination of components in the HRES. The
Fig. 3 Estimated daily-monthly load profile of the resort

\section{Estimated daily load profile in different month in a vear}
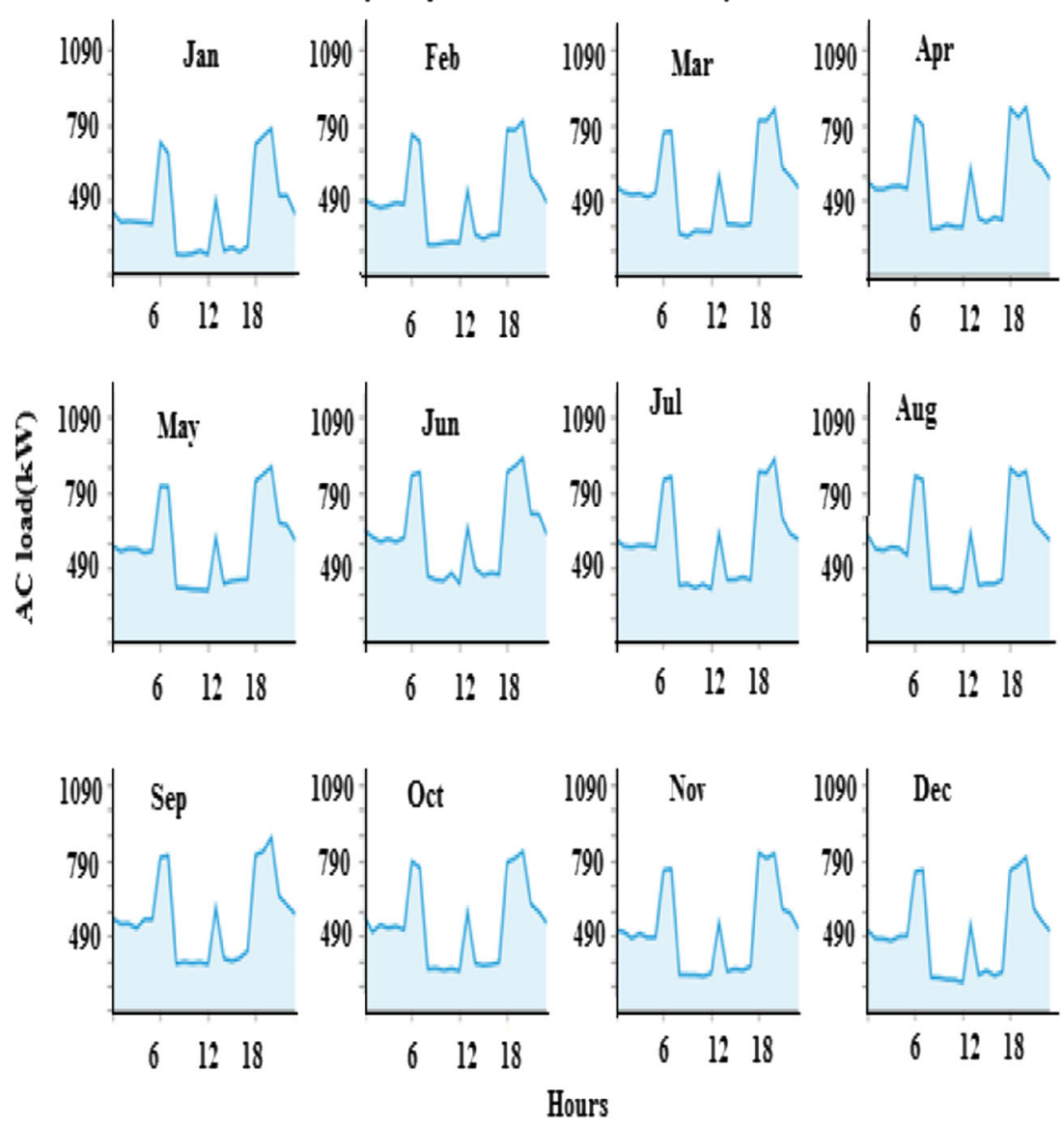
HOMER software has been used to perform this objective, and it is based on the net present cost (NPC) given as.

$C_{-}(n p c, t o t)=C_{-}(a n n, t o t) / C R F\left(i, R_{-} p r o j\right)$

where, $C_{a n n, t o t}$ is the total annualized cost (\$/year), $\mathrm{i}$ is the annual real interest rate $(\%), R_{\text {proj }}$ is the project lifetime (year), CRF represents the capital recovery factor. The CRF is given by the following equation,

$$
C R F(i, N)=\left(i(1+i)^{\wedge} N\right) /\left((1+i)^{\wedge} N-1\right)
$$

where, $\mathrm{N}$ is number of years. HOMER do not use nominal interest rate in the computations but real interest rate is computed from real interest rate using following equation.

$i=\left(i^{\prime}-f\right) /(1+f)$

In Eq. 3, $\mathrm{f}$ is the annual inflation rate and $\mathrm{i}^{\prime}$ is the nominal interest rate. The lifetime of the project was considered 25 years with zero capacity shortage. The discount and

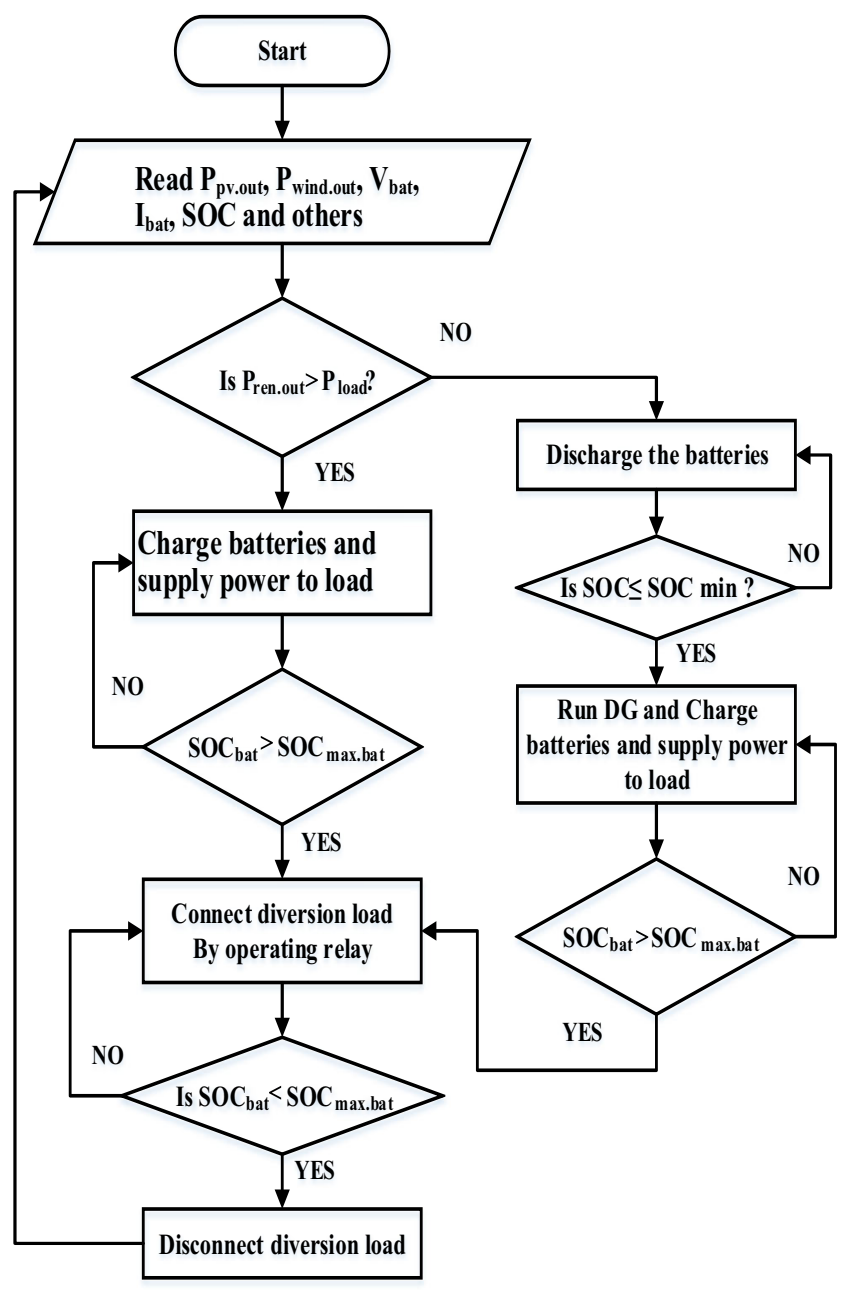

Fig. 4 Flow chart of power management for HRES including diversion load inflation rate for this study were considered $8 \%$ and $2 \%$, respectively. The system cost in HOMER software was simulated in US dollars (\$USD).

The price of per kWh of electricity is called cost of energy (COE). The COE is computed by dividing total annualized cost by annual electricity served to load which is defined as follows.

$C O E=C_{-}($ann, tot $) / L_{-}($ann, load $)$

To calculate the $\mathrm{CO}_{2}$ emissions from the hybrid energy system the following supporting equations has been introduced:

${ }_{t C} O_{2}=3.667 \times m_{f} \times H V_{f} \times C E F_{f} \times X_{c}$

where,

$$
\begin{aligned}
t C O_{2} & =\text { Amount of } \mathrm{CO}_{2} \text { emissions. } \\
m_{f} & =\text { Fuel quantity (Liter) } \\
H V_{f} & =\text { Fuel heating value }(\mathrm{MJ} / \mathrm{L}) \\
C E F_{f} & =\text { Carbon emission factor (ton carbon/TJ) } \\
X_{c} & =\text { Oxidized carbon fraction. }
\end{aligned}
$$

Another factor must be taken into account that is 3.667 $\mathrm{g}$ of $\mathrm{CO}_{2}$ contains $1 \mathrm{~g}$ of carbon. The other components are also detrimental to health as well. It expects that all that carbon gets discharged as either unburned hydrocarbons, $\mathrm{CO}$, or $\mathrm{CO}_{2}$. So, need to enter the outflows components for unburned hydrocarbons and CO. So, HOMER software can compute the amount of the aggregated carbon gets discharged in those two structures [35-37]. The rest gets discharged as $\mathrm{CO}_{2}$. Commonly, just a small division of the carbon gets discharged as hydrocarbon and $\mathrm{CO}$, so almost every last bit of it gets transmitted as $\mathrm{CO} 2$. On the off chance that needs to intrigue just in $\mathrm{CO}_{2}$, need to set the UHC and $\mathrm{CO}$ emanations elements to zero $[38,39]$.

\section{Results and Discussion}

The modeling and simulation results have been processed by the HOMER software. According to the power management algorithm, the cost of energy and other parameters have been analyzed accurately. The optimized outcomes for a specific group of sensitivity parameters affiliated with average wind speed, global horizontal solar radiation, highest yearly capacity shortage, diesel cost, and renewable fraction are represented emphatically in that optimization software. An optimal hybrid renewable energy system has been designed by HOMER renewable energy software through large number of hourly simulations periodically. Various values for wind speed, solar radiation, diesel cost and least renewable fraction have been contemplated with simulations and these values assuring much more suppleness in the analysis. Figure 5 shows the simulation results considering an off-grid hybrid wind-diesel-battery diesel 


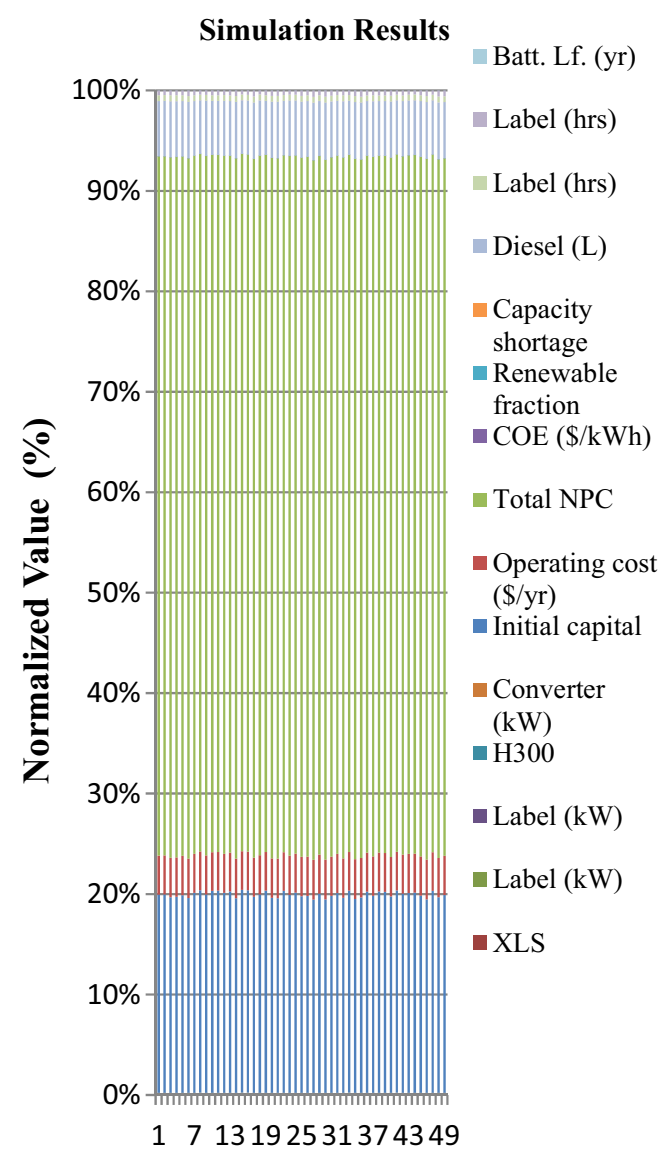

Fig. 5 Overview of simulation results

cost of $0.4 \$ / \mathrm{L}$, highest capacity shortage of $0.03 \%$.USD has been considered as the currency for all costs related with that hybrid system. Figure 6 shows the detail calculation, simulation results and cost analysis with system architecture, NPC, COE, Operating cost, Electrical energy produced by wind turbine diesel generator system, unmet load, excess

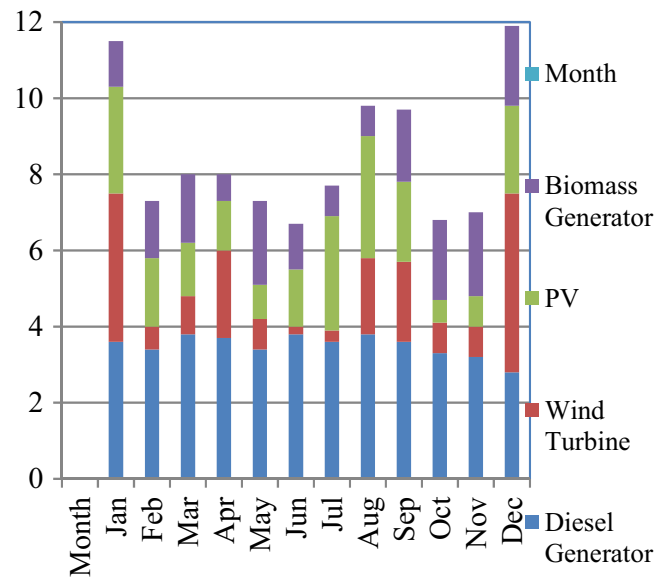

Fig. 6 Energy generated with practicability from the off-grid hybrid PV-diesel-wind-battery system electricity, capacity shortage and renewable fraction of the most monetarily practicable hybrid energy system relevant for the preferred area in both simple case and best cast. At the same time, with a base NPC of USD 160,626 and base COE of USD $0.431 / \mathrm{kWh}$, an off-grid hybrid PV, wind turbine, diesel generator and battery hybrid system is efficiently more feasible and this is observed by the sensitivity analysis. A hybrid energy system can be considered as a most feasible renewable energy system constituted of $18 \mathrm{~kW}$ PV module, two wind turbines ( $10 \mathrm{~kW}$ every), a diesel generation with a divisional power of $15 \mathrm{~kW}$ (utilizing $3 \mathrm{~kW}$ ) and 25 storage batteries in cementation to $3 \mathrm{~kW}$ converters. In Fig. 7 the cost curve of wind turbines have been shown.

The simulation results reflect the analysis related with all the components. Be that as it may, in the remain solitary mode, the renewable vitality sources go about as present sources nourishing straightforwardly the heaps and the battery bank goes about as a voltage source controlling the $\mathrm{AC}$ transport voltage by charging or releasing. The battery converter directs the greatness and recurrence of the heap voltage. The individual RES units can be utilized for maximum power point tracking frameworks to have the most extreme power from the sun oriented PV and twist frameworks in the network associated mode. A similar thing can be relevant in the remaining solitary mode that the battery bank exists as a voltage source to control the $\mathrm{AC}$ transport voltage by charging or releasing.

As reported by the investigation and recreation comes about $\mathrm{CO}_{2}$ emanations rate every year has been discovered 84689.023 Kilotons, which is 16 tones not as much as the customary power plants considering every year as in 2015 for Malaysian viewpoint [40]. The NPC can be shifted by fuel cost, hardware cost, life time, operation and upkeep cost. From that investigation, it can be unmistakably recognized that the NPC for the proposed cross breed vitality framework has been decreased in examination with the NPC

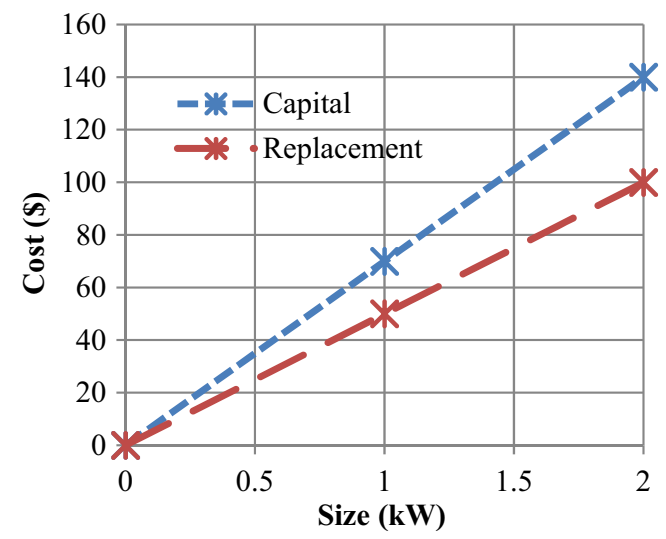

Fig. 7 Cost curve of wind turbine with the replacement and maintenance cost 
Table 2 Comparison of $\mathrm{CO}_{2}$ emission and NPC between the HRES and Conventional Power Plant

\begin{tabular}{lll}
\hline Parameters & Wind-Diesel Hybrid Energy System & Conventional Power Station \\
\hline $\mathrm{CO}_{2}$ Emission /Year (Kt) & $17,347.984$ & $189,467.00$ \\
$\mathrm{NPC} /$ Year $(\$)$ & $160,626.00$ & $293,000.00$ \\
\hline
\end{tabular}

for the traditional power station in Malaysian viewpoint as described in Table 2. The NPC for the planned mixture vitality framework is $29.65 \%$ which is not as much as the NPC for the traditional power plant considering every year the time of 2009 for Bangladesh atmosphere [41].

\section{Conclusions}

In Summary, oil and gas transportation to remote and decentralized area are very challenging issue and time consuming This optimization proposed a hybrid wind-diesel energy system for providing power supply to an off-grid community in isolated islands of specific countries. A detailed simulation has been performed by HOMER software considering manufacturing cost and efficiency for the proposed optimized hybrid wind-diesel energy system. The simulation results confirm that the COE of the optimized system is about USD $0.431 / \mathrm{kWh}$ and the NPC of the optimized system is about USD $160,626.00$. The total sensitivity analysis, optimization and simulation process has been carried out by HOMER software. The proposed hybrid system also ensured the reduction of $\mathrm{CO}_{2}$ emission about 1600 tons per annum which indicates a significant environmentally friendly effort. From the simulation results, it is clearly indicated that the proposed hybrid energy system is economically and environmentally feasible in comparison with other conventional power generation systems. As the generator can decrease the issue would bear sienna wind turbines or small scale integrated micro turbines. These hybrid energy systems can provide enhanced execution in correlation with alternate energy systems; furthermore we attempted to lessen the expense of force era, contrasted with the routine hybrid renewable energy systems. Sooner rather than later, some more helpful renewable vitality models and legitimate control energy systems can be presented for the hybrid vitality energy systems for the remote zones of the world. According to the optimization and simulation results it can be concluded that the proposed optimized hybrid wind-diesel renewable energy system will be applicable to all over the world where environment, climate, weather and meteorological conditions are comparable and predictable. For example, the countries are Australia, Indonesia, Bangladesh, Myanmar, Thailand, Singapore and other countries would be very potential zone for applicable this optimized hybrid wind-diesel renewable energy system.
Acknowledgements The work presented in this paper is part of an on-going research project. The authors would like to thank University of Southern Queensland Postgraduate Research Grant for providing support to Higher Degree Research (HDR) students.

\section{References}

1. Kumar S (2016) Assessment of renewables for energy security and carbon mitigation in Southeast Asia: the case of Indonesia and Thailand. Appl Energy 163:63-70

2. Shezan S, Saidur R, Hossain A, Chong W, Kibria M (2015) Performance analysis of solar-wind-diesel-battery hybrid energy system for KLIA Sepang station of Malaysia. In: IOP conference series: materials science and engineering, p 012074

3. Marano V, Rizzo G, Tiano FA (2012) Application of dynamic programming to the optimal management of a hybrid power plant with wind turbines, photovoltaic panels and compressed air energy storage. Appl Energy 97:849-859

4. Chen HH, Kang H-Y, Lee AH (2010) Strategic selection of suitable projects for hybrid solar-wind power generation systems. Renew Sustain Energy Rev 14:413-421

5. Shezan S, Farzana M, Hossain A, Ishrak A (2015) Techno- economic and feasibility analysis of a micro-grid wind-DG-battery hybrid energy system for remote and decentralized areas. Intern J Adv Eng Technol (IJAET) 8:874-888

6. Ringel M (2006) Fostering the use of renewable energies in the European Union: the race between feed-in tariffs and green certificates. Renew Energy 31:1-17

7. Saber AY, Venayagamoorthy GK (2011) Plug-in vehicles and renewable energy sources for cost and emission reductions. IEEE Trans Indust Elect 58:1229-1238

8. Kantas AB, Cobuloglu HI, Büyüktahtakın İE (2015) Multi-source capacitated lot-sizing for economically viable and clean biofuel production. J Cleaner Prod 94:116-129

9. Wesseh PK Jr, Lin B (2015) Renewable energy technologies as beacon of cleaner production: a real options valuation analysis for Liberia. J Cleaner Prod 90:300-310

10. Solangi K, Islam M, Saidur R, Rahim N, Fayaz H (2011) A review on global solar energy policy. Renew Sustain Energy Rev 15:2149-2163

11. Zhou H, Bhattacharya T, Tran D, Siew TST, Khambadkone AM (2011) Composite energy storage system involving battery and ultracapacitor with dynamic energy management in microgrid applications. IEEE Trans Power Elect 26:923-930

12. Al-Ajlan S, Al-Ibrahim A, Abdulkhaleq M, Alghamdi F (2006) Developing sustainable energy policies for electrical energy conservation in Saudi Arabia. Energy Pol 34:1556-1565

13. Son Y-S, Pulkkinen T, Moon K-D, Kim C (2010) Home energy management system based on power line communication. IEEE Trans Consumer Elect 56:1380-1386

14. Alyousef Y, Stevens P (2011) The cost of domestic energy prices to Saudi Arabia. Energy Pol 39:6900-6905

15. Byun J, Hong I, Kang B, Park S (2011) A smart energy distribution and management system for renewable energy distribution and context-aware services based on user patterns and load forecasting. IEEE Trans Consum Elect 57:436-444 
16. van Hoof B, Lyon TP (2013) Cleaner production in small firms taking part in Mexico's sustainable supplier program. J Cleaner Prod 41:270-282

17. Teo T, Logenthiran T, Woo W (2015) Forecasting of photovoltaic power using extreme learning machine. In: 2015 IEEE innovative smart grid technologies-Asia (ISGT ASIA), pp 1-6

18. Ulutas F, Alkaya E, Bogurcu M, Demirer GN (2012) The national capacity assessment on cleaner (sustainable) production in Turkey. Sustain Cities Soc 5:30-36

19. Yoon C, Bai H, Beres RN, Wang X, Bak CL, Blaabjerg F (2016) Harmonic stability assessment for multiparalleled, grid-connected inverters. IEEE Trans Sustain Energy 7:1388-1397

20. Shezan SA, Saidur R, Ullah KR, Hossain A, Chong WT, Julai S (2015) Feasibility analysis of a hybrid off-grid wind-DG-battery energy system for the eco-tourism remote areas. Clean Technol Environ Pol 17:2417-2430

21. Shezan SA, Julai S, Kibria M, Ullah K, Saidur R, Chong W, Akikur RK (2016) Performance analysis of an off-grid windPV (photovoltaic)-diesel-battery hybrid energy system feasible for remote areas. J Cleaner Prod 125:121-132

22. Dulal HB et al (2013) Renewable energy diffusion in Asia: can it happen without government support? Energy Pol 59:301-311

23. Baños R et al (2011) Optimization methods applied to renewable and sustainable energy: a review. Optim Methods Appl Renew Sustain Energy: A Rev 14:1753-1766

24. Krozer Y (2013) Cost and benefit of renewable energy in the European Union. Renew Energy 50:68-73

25. Rumbayan M, Abudureyimu A, Nagasaka K (2012) Mapping of solar energy potential in Indonesia using artificial neural network and geographical information system. Renew Sustain Energy Rev 16:1437-1449

26. Sovacool BK (2010) A comparative analysis of renewable electricity support mechanisms for Southeast Asia. Energy 34:1779-1793

27. Blum NU, Wakeling RS, Schmidt TS (2009) Rural electrification through village grids-Assessing the cost competitiveness of isolated renewable energy technologies in Indonesia. Renew Sustain Energy Rev 22:482-496

28. Rashid S, Rana S, Shezan S, AB Karim S, Anower S (2016) Optimized design of a hybrid PV-wind-diesel energy system for sustainable development at coastal areas in Bangladesh. In: Environmental progress \& sustainable energy, pp 1-8
29. Palash MM, Shezan SA, Kusum F, Arnat R, Shaila S (2016) Feasibility and techno-economical analysis of an off-grid solar-wind biomass hybrid energy system. Imperial J Interdis Res 2

30. Liserre M, Sauter T, Hung John Y (2010) Future energy systems: integrating renewable energy sources into the smart power grid through industrial electronics. IEEE Indust Elect Mag 4:18-37

31. Kanchev H, Lu D, Colas F, Lazarov V, Francois B (2011) Energy management and operational planning of a microgrid with a PVbased active generator for smart grid applications. IEEE Trans Indust Elect 58:4583-4592

32. Garrity TF (2008) Getting smart. IEEE Power Energy Mag 6:3845

33. Hatziargyriou N, Asano H, Iravani R, Marnay C (2007) Microgrids. IEEE Power Energy Mag 5:78-94

34. Yu FR, Zhang P, Xiao W, Choudhury P (2011) Communication systems for grid integration of renewable energy resources. IEEE Netw 25:22-29

35. Zacharias P, Teodorescu R, Cortés Rodríguez P, Liserre M, Knapp $\mathrm{W}$, Spagnuolo G et al (2010) Renewable energy operation and conversion schemes: a summary of discussions during the seminar on renewable energy systems. IEEE Indust Elect Mag 4:38-51

36. Ipakchi A, Albuyeh F (2009) Grid of the future. IEEE Power Energy Mag 7:52-62

37. Saber AY, Venayagamoorthy GK (2010) Efficient utilization of renewable energy sources by gridable vehicles in cyber-physical energy systems. IEEE Syst J 4:285-294

38. Fathima AH, Palanisamy K (2015) Optimization in microgrids with hybrid energy systems-a review. Renew Sustain Energy Rev 45:431-446

39. Rezzouk H, Mellit A (2015) Feasibility study and sensitivity analysis of a stand-alone photovoltaic-diesel-battery hybrid energy system in the north of Algeria. Renew Sustain Energy Rev 43:1134-1150

40. Shezan S, Das N, Mahmudul H (2017) Techno-economic analysis of a smart-grid hybrid renewable energy system for Brisbane of Australia. Energy Procedia 110:340-345

41. Shezan SA, Hossain A, Ishrak A (2015) A complete off-grid PV-diesel-battery hybrid energy system with feasibility analysis, system modeling and optimization. In: Proceedings of the international conference on mechanical, industrial and materials engineering 2015 (ICMIME2015), p 7, no 68 